\title{
Comparative study of the effects of percutaneous ethanol injection and radiofrequency ablation in cases treated with a straight or expandable electrode
}

\author{
KAZUTAKA KUROKOHCHI $^{1,2}$, AKIHIRO DEGUCHI ${ }^{1}$, TSUTOMU MASAKI ${ }^{1}$, \\ HIROHITO YONEYAMA ${ }^{1}$, TAKASHI HIMOTO ${ }^{1}$, HISAAKI MIYOSHI ${ }^{1}$, \\ HAMDY SAAD MOHAMMAD ${ }^{1}$, TOMOHIKO TAMINATO ${ }^{2}$ and SHIGEKI KURIYAMA ${ }^{1}$ \\ ${ }^{1}$ Department of Gastroenterology and Neurology, ${ }^{2}$ Department of Laboratory Medicine, \\ Kagawa University School of Medicine, 1750-1 Ikenobe, Miki-cho, Kita-gun, Kagawa 761-0793, Japan
}

Received June 28, 2007; Accepted August 6, 2007

\begin{abstract}
Radiofrequency ablation (RFA) has become mainstream among non-surgical treatment modalities in clinical settings for the treatment of hepatocellular carcinoma. We have previously described the novel combination therapy of percutaneous ethanol injection and RFA (PEI-RFA) and reported that this combination therapy was more effective than RFA alone in terms of the induced volume of coagulated necrosis and the energy requirement for the treatment. RFA instruments are mainly divided into two types according to the electrode used, either the straight or expandable type electrode. Although PEI-RFA can be performed by either of the electrodes, there may be some important differences in PEI-RFA according to the type of electrode used. In the present study, the effect of using the straight or expandable electrode in PEI-RFA was evaluated by analyzing the ablation time, volume of coagulated necrosis, the energy requirement for ablation and the amount of injected ethanol into HCC. The comparative study showed that ablation time, total energy requirement and per unit volume of energy requirement for whole and marginal coagulated necrosis were significantly smaller in the group treated with the expandable electrode (E group) than those in the group treated with the straight electrode (S group). The volume of coagulated necrosis was similar between these groups. In group E, the amount of injected ethanol showed a positive correlation with the volume
\end{abstract}

Correspondence to: Drs Kazutaka Kurokohchi and Shigeki Kuriyama, Department of Gastroenterology, Kagawa University School of Medicine, 1750-1 Ikenobe, Miki-cho, Kita-gun, Kagawa 761-0793, Japan

E-mail: kuroko@med.kagawa-u.ac.jp

Key words: hepatocellular carcinoma, percutaneous ethanol inejection therapy, radiofrequency ablation, straight electrode, expandable electrode of coagulated necrosis and the size of the tumors. These results suggest that prior injection of ethanol works mainly by shortening the time and energy requirement for ablation in the time-lag PEI-RFA using the expandable electrode. Thus, prior injection of ethanol before RFA may make RFA treatment less invasive in the time-lag PEI-RFA using the expandable electrode as previously shown HCC cases treated with straight electrode.

\section{Introduction}

Hepatocellular carcinoma (HCC) is a common malignancy worldwide $(1,2)$. For the treatment of HCC, several treatment modalities such as surgical resection, intervention radiology, liver transplantation and local ablation are utilized according to the characteristics of the tumor and the degree of hepatic reserve of cirrhotic liver. For HCC patients that are not suitable for surgical treatment, local treatments may be preferred. Local treatments such as percutaneous ethanol injection (PEI), percutaneous microwave coagulation therapy (PMCT), cryoablation and radiofrequency ablation (RFA) are currently available. Among these local treatments, RFA now plays a central role because it induces wider coagulated necrosis in fewer sessions compared with PEI (3-5). Although the RFA technique has many benefits including simplicity, achievement of certain therapeutic effects on HCC or metastatic liver cancer $(6,7)$, lack of serious side-effects and longer survival interval than PEI $(8,9)$, the extent of coagulated necrosis achievable by RFA is still limited and early tumor recurrence or new tumor formation occurs in other locations. To improve RFA treatment, we developed a novel combination therapy of percutaneous ethanol, ethanol-lipiodol injection and RFA (PEI-RFA and PELI-RFA) and reported that these combination therapies could induce wider coagulated necrosis with a smaller energy requirement (10-12). RFA instruments are divided into straight and expandable types according to the electrode inserted into the tumors. Although PEI-RFA can be done using either of the electrodes, there are some characteristic differences between these electrodes with each electrode having advantages and disadvantages. In our previous reports, our analysis of PEI-RFA was done using a Cool-tip 
RFA system equipped with a straight type electrode. In the present study, the PEI-RFA technique was compared using the straight or expandable electrode and measuring the volume of induced coagulated necrosis and energy requirement for inducing coagulated necrosis. We recently reported that timelag performance of RFA after injecting ethanol (time-lag PEI-RFA) was effective in producing a comparable area of coagulated necrosis with smaller energy requirements than RFA alone (13). Thus, time-lag PEI-RFA was used in the present study.

\section{Materials and methods}

Patients. Thirty-nine patients with HCC were allocated to receive Time-lag PEI-RFA with either the straight or expandable electrode. Time-lag PEI-RFA using the straight type electrode was performed in 24 cases ( 15 males and 9 females; mean age of 64 years) with HCC (ranging between 1.0 and $4.0 \mathrm{~cm}$ in diameter) by Cool-tip RF system. Time-lag PEI-RFA with expandable electrode was performed in 15 cases (12 males and 3 females; mean age of 65 years) with HCC (ranging between 1.5 and $2.5 \mathrm{~cm}$ in diameter) by RTC system. All of these studies were conducted with informed consent from the patients at the time of enrollment (Table I).

Treatments. Time-lag PEI-RFA was performed under realtime US guidance with a $3.5-\mathrm{MHz}$ sector probe (13). RFA was performed by a RTC system (RF3000 Generator, Boston Scientific, USA) with a 3-cm-long expandable LeVeen Needle Electrode (Boston Scientific) and a Cool-tip RF system (Radionics, Burlington, MA, USA) with a 3-cm-long straight type of electrode according to the method described previously (10-12). Briefly, a 17-gauge RFA needle with an electrode of $3 \mathrm{~cm}$ in length (Cool-tip straight electrode and RTC expandable electrode) was inserted into the center of tumor, and then a 21-gauge PEI needle was inserted into the tumor in the liver through the same attachment hole beside the echo probe. The mixture of ethanol (99.8) was slowly injected into the tumor. The volume of injected ethanol was always kept to less than double the estimated tumor volume. Ablation was started $5 \mathrm{~min}$ after completing the ethanol injection.

Time-lag PEI-RFA using the Cool-tip RF system equipped with a straight electrode. Ablation was started at $30 \mathrm{~W}$ of output power and increased $20 \mathrm{~W}$ every 2-3 min in a stepwise fashion. At $50 \mathrm{~W}$ of output power, the circulating cooling water was stopped and the temperature of the RFA electrode was checked. The ablation was terminated when the temperature of the RFA needle exceeded $65^{\circ} \mathrm{C}$.

Time-lag PEI-RFA using the RTC system equipped with an expandable electrode. After injecting ethanol, RFA was performed with a half-opened umbrella until the first roll-off, and then the ablation was performed with full-opened umbrella until the second roll-off.

Evaluation of therapeutic efficacy. Five to seven days after the treatment, plain or contrast enhanced CT was performed to evaluate the response to time-lag PEI-RFA. Tumor necrosis

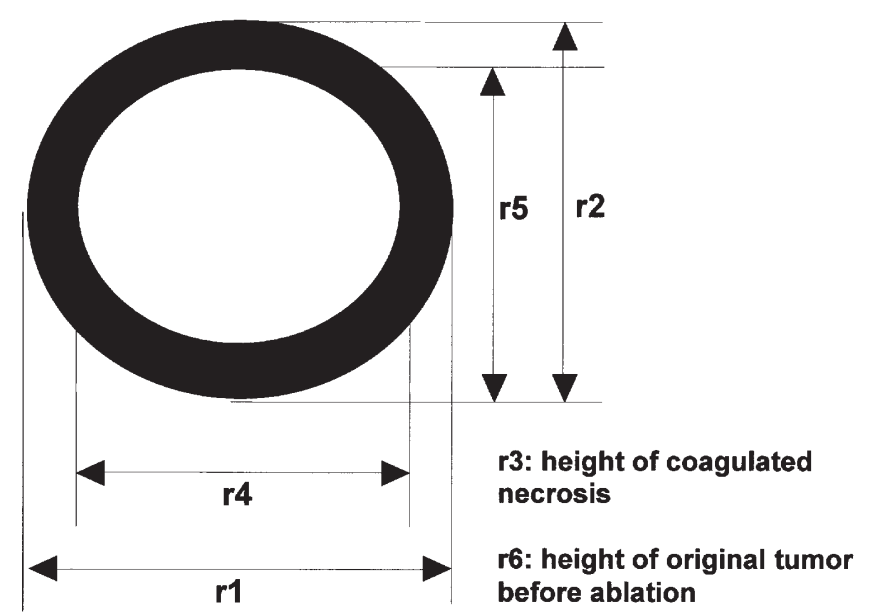

Figure 1. Schematic diagram for calculating the volume of the safety margin area. The white circle shows the HCC tumor before treatment and the black area shows the low density area around the tumor exhibited in the late phase of dynamic CT after treatment. The equation for calculating the volume of the safety margin area is described in the methods section.

was considered to be complete when no foci of early enhancement were seen around the original regions.

Calculation of the volume of coagulated necrosis and energy requirement for ablation. Size of the tumor, amount of injected ethanol, volume of coagulated necrosis, time for ablation, total energy requirement for inducing coagulated necrosis and per unit volume of energy requirement for inducing whole and marginal coagulated necrosis were analyzed. The energy requirement for ablation was calculated as follows: Energy $(J)=$ Watt $(\mathrm{W}) \times$ Duration of ablation $(\mathrm{S})$. The length of coagulated necrosis of the lesion was measured from the late phase of helical dynamic CT. The approximate volume of whole coagulated necrosis area $\left(\mathrm{V} 1 \mathrm{~cm}^{3}\right)=4 / 3 \pi \times \mathrm{r} 1(\mathrm{~cm}) \mathrm{x}$ $\mathrm{r} 2(\mathrm{~cm}) \times \mathrm{r} 3(\mathrm{~cm}) ;(\mathrm{r} 1=$ longest diameter $/ 2 ; \mathrm{r} 2=$ shortest diameter/2; 3 = height/2), while the volume of tumor lesion before ablation $\left(\mathrm{V} 2 \mathrm{~cm}^{3}\right)=4 / 3 \pi \times \mathrm{r} 4(\mathrm{~cm}) \times \mathrm{r} 5(\mathrm{~cm}) \times \mathrm{r} 6(\mathrm{~cm}) / 2$; (r4 = longest diameter $/ 2 ; \mathrm{r} 5=$ shortest diameter $/ 2 ; \mathrm{r} 6=$ height/2). The volume of marginal coagulation was calculated by subtracting V2 from V1. The scheme for measuring each diameter of the coagulated necrosis and original tumor before and after ablation is depicted in Fig. 1. Per unit volume of energy requirement for whole $\left(\mathrm{J} / \mathrm{cm}^{3}\right)$ and marginal $\left(\mathrm{J} / \mathrm{cm}^{3}\right)$ coagulation $=$ energy $/$ whole coagulated necrosis and energy/ volume of marginal coagulation.

Statistical analysis. Statistical analysis was performed using the StatView II (Version 5.0) software. Statistical significance between the straight and expandable probe groups was analyzed by a non-parametric analysis (Mann Whitney U test) and considered significant when $\mathrm{p}<0.05$.

\section{Results}

Comparative study of ablation time, volume of coagulated necrosis and energy requirement in groups treated with a straight or expandable electrode. Thirty-nine patients with HCC were randomly divided into two groups. One group (24 
Table I. Characteristics of patients enrolled in the present study.

\begin{tabular}{lcc}
\hline & S group & E group \\
\hline Number of patients & 24 & 15 \\
$\quad$ Male/female & $15 / 9$ & $12 / 3$ \\
Age (years) & & \\
$\quad$ Mean & 64 & 65 \\
Range & $48-75$ & $49-72$ \\
Tumor size (cm) & & \\
Mean & 1.9 & 2.1 \\
Range & $1.0-4.0$ & $1.5-2.5$ \\
Injected ethanol (ml) & & \\
Mean & 3.7 & 2.1 \\
Range & $0.5-10$ & $1.5-2.5$ \\
Child-Pugh grade & & \\
A & 16 & 10 \\
B & 7 & 5 \\
C & 1 & 0 \\
\hline
\end{tabular}

patients) received Time-lag PEI-RFA by an RFA instrument equipped with a straight electrode (S group), while the other 15 patients were treated using an RFA instrument equipped with an expandable electrode (E group). No major adverse effects were detected in either group. Comparison of ablation time, the volume of coagulated necrosis and the total and per unit volume of energy required for inducing coagulated necrosis in both groups is summarized in Table II. The tumor size of both groups was not significantly different $(\sim 2 \mathrm{~cm}$ in diameter). Although the volume of coagulated necrosis was comparable between groups $\mathrm{S}$ and $\mathrm{E}$, the time for ablation was significantly shorter in group E compared with that in group $\mathrm{S}$. Therefore, the total energy requirement and per unit volume of energy required for whole and marginal coagulation were significantly lower for the expandable electrode group.

Relationship between the amount of ethanol and the volume of coagulated necrosis in patients treated using the RFA instrument with an expandable electrode. We previously showed that the amount of ethanol was positively correlated with the volume of coagulated necrosis in patients treated with an RFA instrument equipped with a straight electrode (Cool-tip RF system). In the present study, the relationship between the amount of ethanol and the volume of coagulated necrosis was also confirmed in patients treated with the RFA instrument equipped with an expandable electrode, although the correlation was weak ( $\mathrm{r}=0.37, \mathrm{P}=0.04)$ (Fig. 2).

Representative case of HCC treated with time-lag PEI-RFA with an expandable electrode. By analyzing the effects of time-lag PEI-RFA using the expandable electrode on the energy requirement, one important point has emerged. This treatment induces similar coagulated necrosis as the straight electrode but with a smaller energy requirement and in shorter time. In one patient, a HCC ( $2 \mathrm{~cm}$ in diameter) was located in the $\mathrm{S} 8$ region of the liver immediately under the diaphragm (Fig. 3). A HCC immediately under the diaphragm is likely to be difficult to treat with RFA using the straight type of electrode because patient respiration causes movement of the inserted electrode. Moreover, high energy RFA should be avoided due to the potential for burning of the diaphragm. Treatment using an expandable electrode that can be fixed into the tumor and results in ablation in a shorter time with

Table II. Comparison of the volume of coagulated necrosis and energy requirement between the groups treated with expandable and straight electrode.

\begin{tabular}{lccccccccccc}
\hline & $\begin{array}{c}\text { T-S } \\
(\mathrm{cm})\end{array}$ & $\begin{array}{c}\text { ETOH } \\
(\mathrm{ml})\end{array}$ & $\begin{array}{c}\mathrm{L} \\
(\mathrm{cm})\end{array}$ & $\begin{array}{c}\mathrm{S} \\
(\mathrm{cm})\end{array}$ & $\begin{array}{c}\mathrm{H} \\
(\mathrm{cm})\end{array}$ & $\begin{array}{c}\mathrm{V} \\
\left(\mathrm{cm}^{3}\right)\end{array}$ & $\begin{array}{c}\mathrm{M} \\
\left(\mathrm{cm}^{3}\right)\end{array}$ & $\begin{array}{c}\mathrm{D} \\
(\mathrm{min})\end{array}$ & $\begin{array}{c}\text { T-ENE } \\
(\mathrm{J})\end{array}$ & $\begin{array}{c}\mathrm{T}-\mathrm{ENE} / \mathrm{V} \\
\left(\mathrm{J} / \mathrm{cm}^{3}\right)\end{array}$ & $\begin{array}{c}\mathrm{T}-\mathrm{ENE} / \mathrm{M} \\
\left(\mathrm{J} / \mathrm{cm}^{3}\right)\end{array}$ \\
\hline $\begin{array}{l}\text { S group } \\
(\mathrm{n}=24)\end{array}$ & $1.9 \pm 0.8$ & $3.0 \pm 1.9$ & $3.5 \pm 0.6$ & $2.9 \pm 0.5$ & $3.1 \pm 0.6$ & $17.0 \pm 7.2$ & $15.1 \pm 7.4$ & $8.1 \pm 2.2$ & $24500 \pm 9568$ & $1601 \pm 792$ & $1884 \pm 1049$ \\
$\begin{array}{l}\text { E group } \\
(\mathrm{n}=15)\end{array}$ & $2.1 \pm 0.3$ & $3.3 \pm 1.1$ & $3.4 \pm 0.5$ & $3.0 \pm 0.6$ & $3.2 \pm 0.4$ & $18.2 \pm 6.9$ & $16.5 \pm 6.8$ & $5.8 \pm 3.0$ & $17408 \pm 8567$ & $1005 \pm 718$ & $1142 \pm 857$ \\
\begin{tabular}{l} 
P-value \\
\hline
\end{tabular} & 0.45 & 0.67 & 0.70 & 0.39 & 0.55 & 0.63 & 0.59 & 0.01 & 0.03 & 0.03 & 0.03
\end{tabular}

Twenty-four HCCs were treated with time-lag PEI-RFA with straight type electrode, while 15 HCCs were treated with time-lag PEI-RFA with expandable type electrode. After treatment, the longest and the shortest diameters, and the height of the coagulated necrosis were estimated by helical dynamic CT and the approximation volume of total and marginal coagulated necrosis were calculated. Each datum expresses mean value \pm standard deviation. T-S, tumor size; EtOH, amount of ethanol; L, longest diameter; S, shortest diameter; H, height; $\mathrm{V}$, volume of coagulated necrosis; $\mathrm{M}$, volume of marginal coagulation; D, duration of ablation; T-ENE, total energy requirement; TENE/V, energy requirement per unit volume for whole coagulation; T-ENE/M, energy requirement per unit volume for inducing marginal coagulation. 


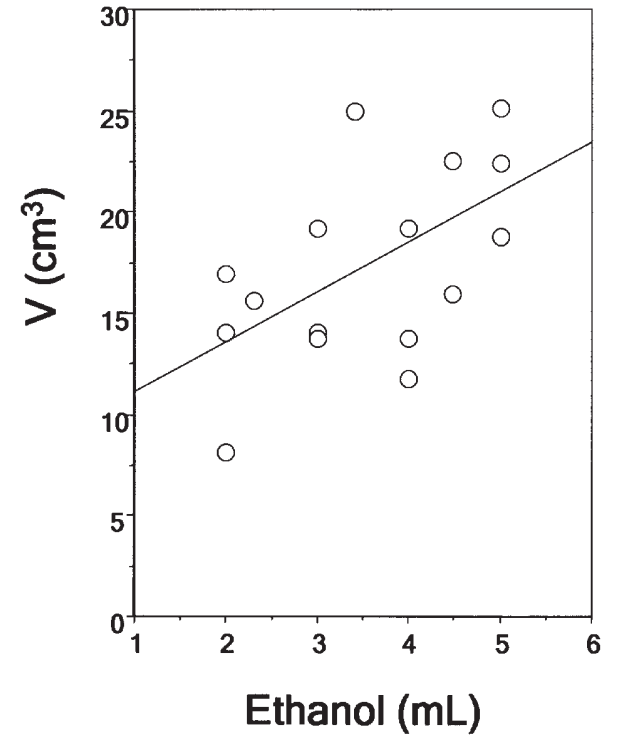

Figure 2. Relationship between the amount of ethanol injected and the volume of coagulated necrosis in time-lag PEI-RFA. Time-lag PEI-RFA was performed in 16 cases of HCC. Ablation was performed using the RTC system. The amount of ethanol injected into tumors positively correlated with the volume of coagulated necrosis $(r=0.37, \mathrm{P}=0.04)$.

lower energy requirements was preferable in this situation. Therefore, the patient underwent time-lag PEI-RFA using the expandable electrode. Five minutes after the injection of $3 \mathrm{ml}$ of ethanol, RFA was performed at $30 \mathrm{~W}$ for $1 \mathrm{~min}$ and $40 \mathrm{~W}$ for $16 \mathrm{sec}$ with a half-opened umbrella until the first roll-off, and then $40 \mathrm{~W}$ for $1 \mathrm{~min}$ and $50 \mathrm{~W}$ for $42 \mathrm{sec}$ with a fullopened umbrella until the second roll-off. The area of coagulated necrosis $(3 \times 2.5 \times 3.5 \mathrm{~cm})$ was induced by the RFA for $2 \mathrm{~min}$ and 58 seconds in total.

\section{Discussion}

RFA has become the mainstream of non-surgical treatment modalities for HCC in clinical settings. However, several limitations of RFA have been pointed out including the limited area of induced, coagulated necrosis by RFA alone and the relatively high rate of local tumor recurrences $(14,15)$. To overcome these limitations of RFA alone, we developed the novel combination therapy of percutaneous ethanol injection and RFA (PEI-RFA) and reported that this combination therapy could induce wider coagulated necrosis with smaller energy requirements (12). We previously reported on the effectiveness of the time-lag performance of RFA after ethanol injection (13) - a study that was triggered by a chance event when PEI-RFA was performed on HCC using an RFA system equipped with an expandable LeVeen needle electrode. When RFA was started 5 min after the injection of ethanol due to a machine malfunction, a roll-off phenomenon suggesting that termination of ablation had occurred unexpectedly early and the total ablation had finished in a short time. Thereafter we observed that most treated patients achieved an unexpected early roll-off after the start of ablation using the instrument with an expandable electrode as shown in a representative case. Based on these observations, we proposed that the time-lag performance of RFA after PEI may be more effective than no time-lag PEI-RFA. Simultaneously, we believed there may be some important differences between the instruments equipped with an expandable or straight type of electrode in the time-lag PEI-RFA. Furthermore, the Cool-tip RF system using the straight type electrode had always been used in the analysis of the PEI-RFA technique to date. Therefore, an analysis focusing on the effects of time-lag PEI-RFA using an expandable electrode was warranted in the present study. It has been recently demonstrated that a multi-step method using the expandable electrode was useful to reduce the ablation time and to suppress the increase in pressure in the tumor $(16,17)$. Our results in the present study showed that the time for ablation, total energy requirement and per unit volume of energy required for whole and marginal coagulated necrosis was significantly smaller in group $\mathrm{E}$ than those in group S. Expandable and straight type electrodes have advantages and disadvantages for inducing coagulated necrosis. For example, the straight electrode is easily inserted into tumors due to the sharp tip and does not require expansion but has disadvantage that it can not be fixed into the liver during ablation leading to the ablation outside the tumor due to the movement of electrode caused by patient respiration. Alternatively, the expandable electrode is able to be fixed

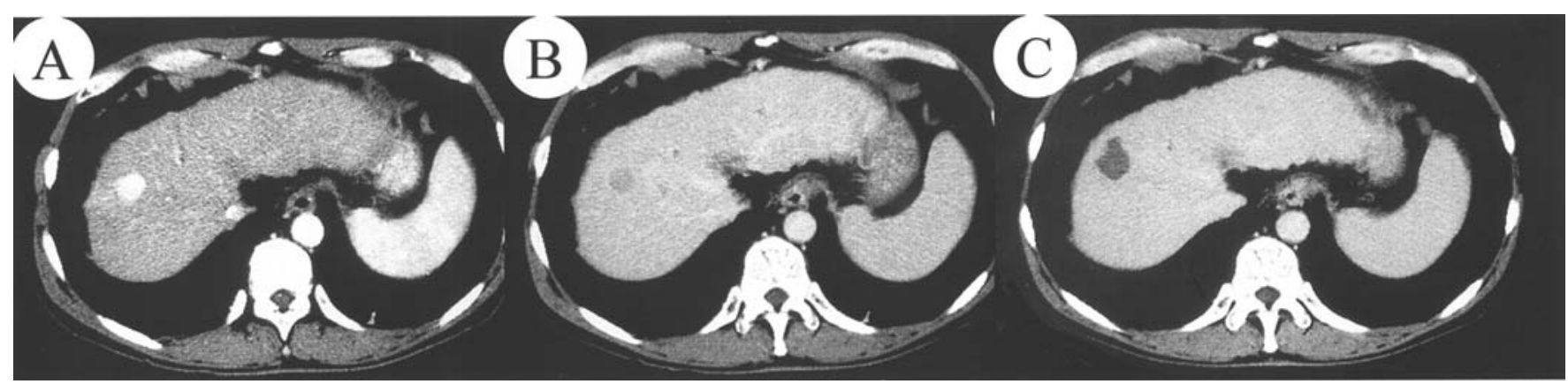

Figure 3. A representative case of HCC treated with time-lag PEI-RFA using an expandable electrode. In this case, ablation was completed within 3 min in total and achieved the coagulated necrosis of $3 \times 2.5 \times 3.5 \mathrm{~cm}$ in the area. A HCC was located immediately under the right diaphragm. Dynamic CT images before (A, early vascular phase; B, delay phase) and after (C, delay phase) time-lag PEI-RFA with the RTC system utilizing an expandable electrode are shown. Five minutes after the injection of $3 \mathrm{ml}$ of ethanol, RFA was performed at $30 \mathrm{~W}$ for $1 \mathrm{~min}$ and $40 \mathrm{~W}$ for 16 sec with half-opened umbrella until the first roll-off, and then $40 \mathrm{~W}$ for $1 \mathrm{~min}$ and $50 \mathrm{~W}$ for $42 \mathrm{sec}$ with full-opened umbrella until the second roll-off. 
into the liver and is not affected by respiration. We need to use either the straight or expandable electrode according to the individual cases of HCC. In our previous study we reported that time-lag PEI-RFA could induce comparable coagulated necrosis compared with no time-lag PEI-RFA, and that timelag PEI-RFA was likely to be less invasive when inducing coagulated necrosis using the Cool-tip RF system with a straight type electrode. The literature reports that HCC is produced on the cirrhotic liver with poor hepatic reserve capacity. In this regard, time-lag PEI-RFA using the RTC system equipped with an expandable electrode is likely to be a less invasive treatment modality for HCC.

In conclusion, time for ablation, the total energy requirement and the per unit volume of energy required for whole and marginal coagulated necrosis were significantly lower in the group treated with an expandable electrode than in the group treated with a straight electrode in time-lag PEI-RFA. Thus, time-lag PEI-RFA is likely to be an effective treatment modality regardless of the type of electrode used in terms of the effects and energy requirement for ablation.

\section{References}

1. Okuda K: Hepatocellular carcinoma. J Hepatol 32: 225-237, 2000.

2. Bruix J, Messheimer AJ, Forner A, Boix L, Vilana R and Llovet JM: New aspects of diagnosis and therapy of hepatocellular carcinoma. Oncogene 25: 3848-3856, 2006.

3. Curley SA, Izzo F, Ellis LM and Vauthey JN: Radio-frequency ablation of hepatocellular cancer in 110 patients with cirrhosis. Ann Surg 232: 381-391, 2000.

4. Livraghi T, Goldberg SN, Lazzaroni S, Meloni F, Ierace T, Solbiati L and Gazelle GS: Hepatocellular carcinome: radiofrequency ablation of medium and large lesions. Radiology 214: 761-768, 2000.

5. Goldberg SN, Gazelle GS, Comon CC, Mueller PR and Tanabe KK: Treatement of intrahepatic malignancy with radiofrequency ablation. Cancer 88: 2452-2463, 2000.

6. Solbiati L, Goldberg SN, Ierace T, Livraghi T, Meloni F, Dellanoce M, Sironi S and Gazelle GS: Hepatic metastases: percutaneous radio-frequency ablation with cooled-tip electrodes. Radiology 205: 367-372, 1997.

7. Solbiati L, Lerace T, Goldberg SN, Sironi S, Livraghi T, Fiocca R, Servadio G, Rizzatto G, Mueller PR, Del Maschio A and Gazelle GS: Percutaneous US-guided radio-frequency tissue ablation of liver metastases: treatment and follow-up in 16 patients. Radiology 202: 195-203, 1997.
8. Lencioni RA, Allgaier H-P, Cloni D, Olschewski M, Deibert P, Crocetti L, Frings H, Laubenberger J, Zuber I, Blum HE and Bartolozzi C: Small hepatocellular carcinoma in cirrhosis: randomized comparison of radio-frequency thermal ablation versus percutaneous ethanol injection. Radiology 228: 235-240, 2003.

9. Livraghi T, Goldberg SN, Lazzaroni S, Meloni F, Solbiati L and Gazelle GS: Small hepatocellular carcinoma: treatment with radio-frequency ablation versus ethanol injection. Radiology 210: 655-661, 1999.

10. Kurokohchi K, Watanabe S, Masaki T, Hosomi N, Funaki T, Arima K, Yoshida S, Nakai S, Murota M, Miyauchi Y and Kuriyama S: Combination therapy of percutaneous ethanol injection and radiofrequency ablation against hepatocellular carcinomas difficult to treat. Int J Oncol 21: 611-615, 2002.

11. Kurokohchi K, Watanabe S, Masaki T, Hosomi N, Funaki T, Arima K, Yoshida S, Miyauchi Y and Kuriyama S: Combined use of percutaneous ethanol injection and radiofrequency ablation for the effective treatment of hepatocellular carcinoma. Int J Oncol 21: 841-846, 2002.

12. Kurokohchi K, Watanabe S, Masaki T, Hosomi N, Miyauchi Y, Himoto T, Kimura Y, Nakai S, Deguchi A, Yoneyama H, Yoshida $\mathrm{S}$ and Kuriyama S: Comparison between combination therapy of percutaneous ethanol injection and radiofrequency ablation and radiofrequency ablation alone for patients with hepatocellular carcinoma. World J Gastroenterol 11: 1426-1432, 2005.

13. Kurokohchi K, Masaki T, Watanabe S, Nakai S, Deguchi A, Morishita A, Yoneyama H, Ohgi T, Ono M, Yoshitake A, Kako T, Ohmachi N, Kiuchi T, Maeta T, Yoshida M, Mori Y, Kohi F and Kuriyama S: Time-lag performance of radiofrequency ablation after percutaneous ethanol injection for the treatment of hepatocellular carcinoma. Int J Oncol 28: 971-976, 2006.

14. Abdalla EK, Vauthey JN, Ellis LM, Ellis V, Pollock R, Broglio KR, Hess K and Curley SA: Recurrence and outcomes following hepatic resection, radiofrequency ablation, and combined resection/ablation for colorectal liver metastases. Ann Surg 239: 818-825, 2004.

15. Kotoh K, Enjoji M, Arimura E, Morizono S, Kohjima M, Sakai H and Nakamuta M: Scattered and rapid intrahepatic recurrence after radiofrequency ablation for hepatocellular carcinoma. World J Gastroenterol 11: 6828-6832, 2005.

16. Nakamuta M, Kohjima M, Morizono S, Yoshimoto T, Miyagi Y, Sakai H, Enjoji M and Kotoh K: Comparison of tissue pressure and ablation time between the LeVeen and cool-tip needle methods. Comp Hepatol 5: 10-14, 2006.

17. Solmi L, Nigro G and Roda E: Therapeutic effectiveness of echo-guided percutaneous radiofrequency ablation therapy with a LeVeen needle electrode in hepatocellular carcinoma. World J Gastroenterol 12:1098-1104, 2006. 